\title{
Gene network and canonical pathway analysis in prostate cancer: a microarray study
}

\author{
Hakan Savli ${ }^{1,4 *}$, Attila Szendröi ${ }^{2 *}$, Imre Romics ${ }^{2}$ \\ and Balint Nagy ${ }^{3}$ \\ ${ }^{1}$ Department of Medical Genetics and Clinical Research Unit \\ Kocaeli University \\ Kocaeli 41380, Turkey \\ ${ }^{2}$ Department of Urology \\ Semmelweis University \\ Budapest 1082, Hungary \\ ${ }^{3}$ Genetic Laboratory \\ $1^{\text {st }}$ Department of Obstetrics and Gynecology \\ Semmelweis University \\ Budapest 1088, Hungary \\ ${ }^{4}$ Corresponding author: Tel, 90-532-660-96-68; \\ Fax, 90-262-303-80-16; E-mail, hakansavli@yahoo.com \\ *These authors contributed equally to this work.
}

Accepted 15 January 2008

Abbreviations: AR, androgen receptor; $\mathrm{BPH}$, benign prostate hyperplasia; IGF, insulin-like growth factor; PCA, prostate cancer; PSA, prostate specific antigen

\begin{abstract}
The molecular mechanism playing a role in the development of prostate cancer (PCA) is not well defined. We decided to determine the changes in gene expression in PCA tissues and to compare them to those in noncancerous samples. Prostate tissue samples were collected by needle biopsy from 21 PCA and 10 benign prostate hyperplasic (BPH) patients. Total RNA was isolated, cDNA was synthesized, and gene expression levels were determined by microarray method. In the progression to PCA, 738 up-regulated and 515 downregulated genes were detected in samples. Analysis using Ingenuity Pathway Analysis (IPA) software revealed that $\mathbf{4 6 6}$ network and $\mathbf{4 2 3}$ functions-pathways eligible genes were up-regulated, and 363 network and 342 functions-pathways eligible genes were down-regulated. Up-regulated networks were identified around IL-1 $\beta$ and insulin-like growth factor-1 (IGF-1) genes. The NFKB gene was centered around two upand down-regulated networks. Up-regulated canonical pathways were assigned and four of them were evaluated in detail: acute phase response, hepatic fibrosis, actin cytoskeleton, and coagulation pathways.
\end{abstract}

Axonal guidance signaling was the most significant down-regulated canonical pathway. Our data provide not only networks between the genes for understanding the biologic properties of PCA but also useful pathway maps for future understanding of disease and the construction of new therapeutic targets.

Keywords: microarray analysis; prostate-specific antigen; prostatic neoplasms

\section{Introduction}

Prostate cancer (PCA) is the second most common cancer in men. This tumor develops slowly, and successful screening protocols can help to reduce mortality and morbidity (Müller and Brenner, 2006). Digital rectal examination and serum prostate specific antigen (PSA) determination are the most commonly used screening methods worldwide. PSA has an excellent sensitivity with a low specificity. There is a great interest to find more reliable diagnostic and prognostic markers. The molecular mechanism playing a role in the development of PCA is not known. The heterogeneity of PCA has been recognized for a long time and varies from asymptomatic to a rapidly fatal systemic malignancy (Hughes et al., 2005; Maitland and Collins, 2005). Molecular biological methods are used to determine similarities and differences, and obtain useful information for effective treatment and prognosis (Quinn et al., 2005).

PCA is the leading cause of death in the US and in Europe. It is a heterogeneous disease and the outcome is difficult to predict. Digital rectal examination and serum PSA level measurements are the main tools in the diagnostic protocols.

Molecular biological methods including immunohistochemistry, comparative genomic hybridization (CGH), CGH-array, microarray analysis, and quantitative real-time PCR determinations have been used in the search to determine the molecular mechanism of the developmentof PCA, and to find new diagnostic and prognostic markers (Hughes et al., 2005; Quinn et al., 2005).

\section{Materials and Methods}

\section{Patients}

Prostate tissue samples were obtained by trans- 
rectal ultrasound guided needle biopsy from nontreated $21 \mathrm{PCA}$ (PCA) and 10 benign prostate hyperplasic (BPH) patients from October of 2005 to March of 2006. The selection of patients was based on digital rectal examinations and on serum PSA levels, and was confirmed by histological examination later. Gleason's grades were assigned. The average age was $72.0 \pm 8.8$ years vs. $64.3 \pm 12.1$ years, respectively. The Ethical Committee of Semmelweis University approved the study and all patients gave informed consent to be involved. Prostate tissue samples were transferred to $1.5 \mathrm{ml}$ Eppendorf tubes containing $0.5 \mathrm{ml}$ of DNA/RNA Stabilization Reagent (Roche, Mannheim, Germany) following the biopsy, and these were kept at $-85^{\circ} \mathrm{C}$ until the RNA isolation.

\section{PSA determination}

Pre-biopsy PSA levels were determined by microparticle enzyme immunoassay (MEIA) on an Abbott IMx using a PSA kit (Abbott Park, IL).

\section{RNA isolation}

During the RNA isolation tissue samples were placed to lysing matrix tubes containing $0.3 \mathrm{ml}$ of RNA lysis buffer and were treated using a FastPrep Bio101 tissue destroyer centrifuge (Thermo Savant, Holbrook, NY). A Perfect RNA Eukaryotic kit was used (Eppendorf, Hamburg, Germany) for RNA isolation from the samples according to the manufacturer's instructions.

\section{Microarray hybridizations}

Applied Biosystems Human Genome Survey Arrays $\mathrm{V} 2.0$, covering 29,098 genes, were used to determine the transcriptional profiles of $21 \mathrm{PCA}$ and $10 \mathrm{BPH}$ samples. DIG-UTP labelled cRNA was generated and linearly amplified from $2 \mu \mathrm{g}$ total RNA using the Chemiluminescent RT-IVT Labeling Kit v 2.0 (Applied Biosystems, Foster City, $\mathrm{CA}$ ) as described by the protocol. Array hybridization, chemiluminescence detection, image acquisition and analysis were performed using Applied Biosystems Chemiluminescence Detection Kit and Applied Biosystems 1700 Chemiluminescence Microarray Analyzer following the manufacturer's instructions.

Briefly, each microarray was first pre-hybridized at $55^{\circ} \mathrm{C}$ for $1 \mathrm{~h}$ in hybridization buffer with blocking reagent. Twenty $\mu \mathrm{g}$ DIG-labeled cRNA targets were first fragmented mixed with internal control target and hybridized to the prehybridized microarrays in a volume of $1.5 \mathrm{ml}$ at $55^{\circ} \mathrm{C}$ for $16 \mathrm{~h}$. After hybridization, the arrays were washed with hybridization wash buffer and chemiluminescence rinse buffer. Enhanced chemiluminescent signals were generated by incubating arrays with alkaline phosphatase conjugated anti-digoxigenin antibody followed by incubation with Chemiluminescence Enhancing Solution and a final addition of Chemiluminescence Substrate. Images were collected for each microarray using the ABI 1700 Chemiluminescent Microarray Analyzer. Images were autogridded and the chemiluminescent signals were quantified, corrected for background and spot and spatially normalized. Obtained data imported into GeneSpring 6.1 software for analysis (GeneSpring 6.1, Silicon Genetics, Redwood City, CA). The fold changes were analyzed by filtering the dataset using $P$-value $<0.01$ and a signal-to-noise ratio $>$ 2 for use in ANOVA statistical analysis. Additional filtering (minimum 2-fold change) was applied to extract the most these gene which were analyzed using Ingenuity Pathway Analysis (IPA) software (Ingenuity Systems, Redwood City, CA). Those genes with known gene symbols (HUGO) and their corresponding expression values were uploaded into the software. Each gene symbol was mapped to its corresponding gene object in the Ingenuity Pathways Knowledge Base. Networks of these genes were algorithmically generated based on their connectivity and assigned a score. The score is a numerical value used to rank networks according to how relevant they are to the genes in the input dataset but may not be an indication of the quality or significance of the network. The score takes into account the number of focus genes in the network and the size of the network to approximate how relevant this network is to the original list of focus genes. The network identified is then presented as a graph indicating the molecular relationships between genes/gene products. Genes are represented as nodes, and the biological relationship between two nodes is represented as an edge (line). The intensity of the node color indicated the degree of up- or down-regulation. Genes in uncolored notes were not identified as differentially expressed in our experiment and were integrated into the computationally generated networks on the basis of the evidence stored in the IPA knowledge memory indicating a relevance to this network. The node shapes denote enzymes ( () , phosphatases $(\triangle)$, kinases $(\nabla)$, peptidases $(\diamond)$, G-protein coupled receptor (घ), transmembrane receptor (G), cytokines $(\square)$, growth factor $(\square)$, ion channel (I), transporter $(\triangle)$, translation factor $(\bullet)$, nuclear receptor ( $\square$ ), transcription factor (๖) and other $(\odot)$. Canonical pathways analysis identified the 
pathways, from the IPA library of canonical pathways, which were most significant to the input data set. The significance of the association between the data set and the canonical pathway was determined based on two parameters: (1) A ratio of the number of genes from the data set that map to the pathway divided by the total number of genes that map to the canonical pathway and (2) a $P$ value calculated using Fischer's exact test determining the probability that the association between the genes in the data set and the canonical pathway is due to chance alone.

\section{Quantitative real-time PCR (Q-RT-PCR)}

cDNA was synthesized using DNase-l-treated total RNA with a First Stand cDNA synthesis kit for RT-PCR (Roche Diagnostic Corp., Indianapolis, IN) according to the manufacturer's instructions. Quantitative PCR were performed using a LightCycler (Roche) as reported previously (Savli et al., 2002) for determination of Fas, IL-1 $\beta$, P21, and CXCR4 gene expressions. $\beta 2$-microglobulin gene was used

Table 1. List of the primers used for the quantitative RT-PCR.

p21

TGA GCG ATG GAA CTT CGA CT

GAC AGT GAC AGG TCC ACA TGG

$\beta 2$-Microglobulin

TGA CTT TGT CAC AGC CCA AGA TA

AAT CCAAAT GCG GCA TCT TC

Fas

ACT GTG ACC CTT GCA CCA AAT-

GCC ACC CCA AGT TAG ATC TGG

IL1 $\beta$

GTGCTGAATGTGGACTCAATCC

TGACAGAGGAGGGTTTCTTAGAAC

CXCR4

CCGCTTCTACCCCAATGACT

GCGAAGAAAGCCAGGATGAG as the internal control. Gene sequences are shown in Table 1. The Relative Quantification REST software package (SPSS, Chicago, IL) was used for the statistical evaluation of the data.

\section{Results}

Differentially expressed genes are shown in two separate tables. The 100 most up-regulated genes (PCA samples compared to $\mathrm{BPH}$ samples) are shown in Supplementary Table 1. The 100 most down-regulated genes (BPH samples compared to PCA samples) are shown in Supplementary Table 2 . Both sets of results were obtained as two-fold values. Table 2 indicates the gene expression results of four genes (Fas, IL-1 $\beta$, P21, CXCR4), obtained by Real Time PCR and microarray methods. These results are in a good agreement.

In the progression to PCA 738 up-regulated genes were detected. We investigated interactions using the Ingenuity Pathway Analysis (IPA) software and found 466 network eligible genes and 423 Functions-Pathways eligible genes. Figure 1 shows the most significant three gene networks of over-expressed genes in PCA samples. Top functions of these genes were related to cellular movement, hematological system development, immune response, cell signaling, molecular transport, vitamin and mineral metabolism, cancer, reproductive system, gene expression. These networks identified around IL-1 $\beta$, IGF-1 and NFKB genes.

Table 3 lists the top ten canonical pathways that are up-regulated. Supplementary Figure 1 shows the canonical pathway of acute phase response signaling, and Supplementary Figure 2 shows the canonical pathway of the coagulation system. Supplementary Figure 3 shows the canonical pathway of hepatic fibrosis/hepatic stellate cell activation in diagrammatic form.

In the progression to PCA 449 down-regulated genes were detected. We investigated interactions using the IPA and found 363 network eligible genes, and 342 Functions-Pathways eligible genes. Figure 2 shows a gene network and down-regulated

Table 2. Summarized real time PCR confirmation results of the four genes.

\begin{tabular}{lcl}
\hline \multicolumn{1}{c}{ Genes } & Ratios obtained by real-time PCR & Ratios obtained by arrays \\
\hline IL-1 $\beta$ (interleukin-1 beta precursor) & 2418,673 (Up-regulated) & 2,541 (Up-regulated) \\
Chemokine (C-X-C motif) receptor 4 & 7,754 (Up-regulated) & 2,006 (Up-regulated) \\
Fas (TNF receptor superfamily, member 6) & 44,663 (Up-regulated) & 2,664 (Up-regulated) \\
Cyclin-dependent kinase inhibitor 1A (p21, Cip1) & 221,168 (Down-regulated) & 3,153 (Down-regulated) \\
\hline
\end{tabular}



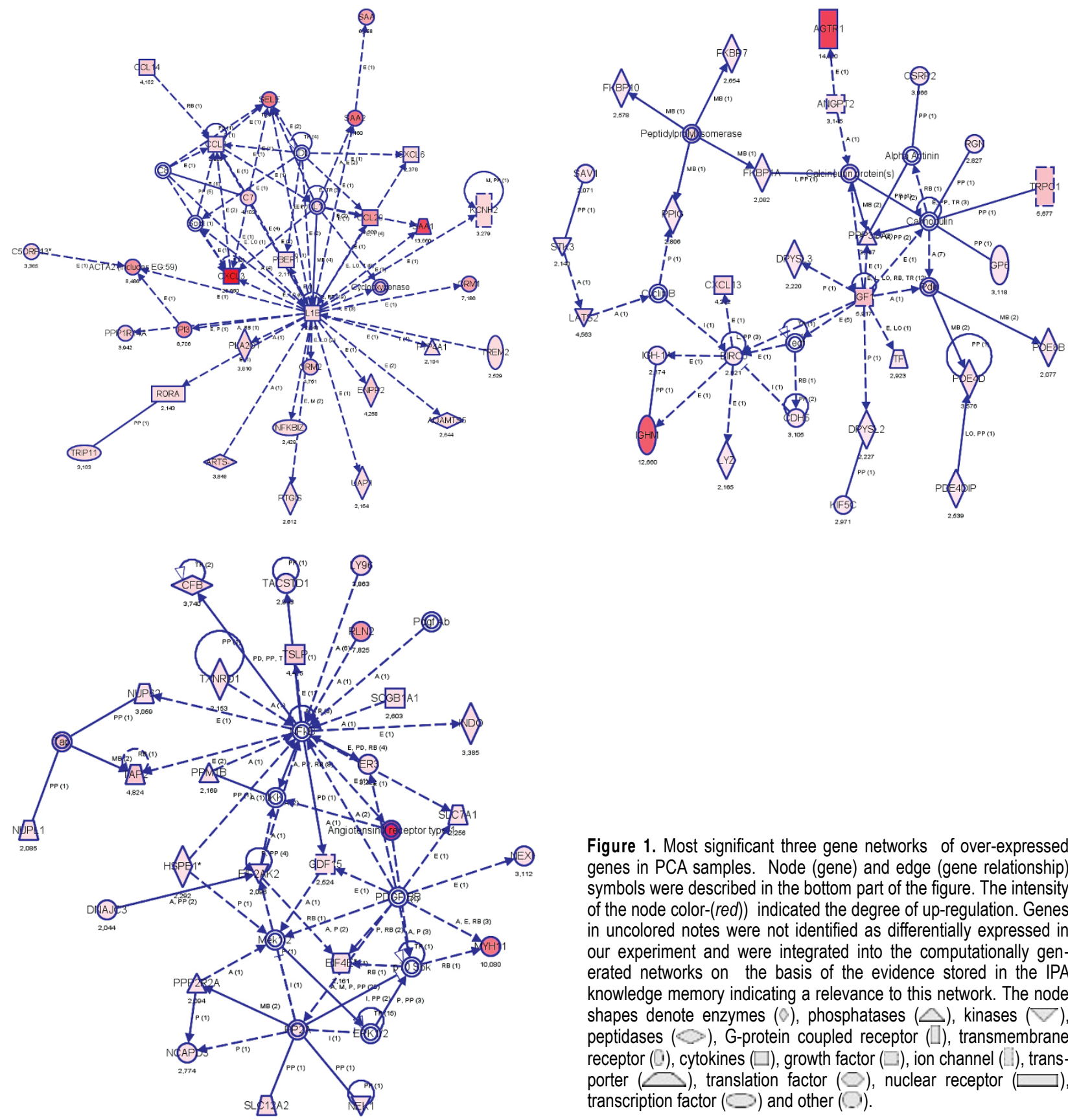

Figure 1. Most significant three gene networks of over-expressed genes in PCA samples. Node (gene) and edge (gene relationship) symbols were described in the bottom part of the figure. The intensity of the node color-(red)) indicated the degree of up-regulation. Genes in uncolored notes were not identified as differentially expressed in our experiment and were integrated into the computationally generated networks on the basis of the evidence stored in the IPA knowledge memory indicating a relevance to this network. The node shapes denote enzymes $(\diamond)$, phosphatases $(\triangle)$, kinases $(\nabla)$, peptidases $(\bigcirc)$, G-protein coupled receptor $(\square)$, transmembrane receptor $(\square)$, cytokines $(\square)$, growth factor $(\square)$, ion channel ( $\square$ ), trans-

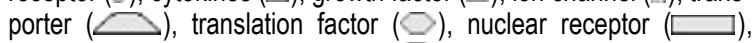
transcription factor $(\square)$ and other $(\bigcirc)$.

genes in PCA. The main functions of the genes were related to cellular assembly and organization, connective tissue development and function, and neurological disease, and were identified around the NFKB gene.

Table 4 lists the top ten canonical pathways that are down-regulated. Supplementary Figure 4 shows the canonical pathway of antigen presentation and Supplementary Figure 5 shows the cellular localization of the genes and their functions in the axonal guidance signaling pathway.

\section{Discussion}

PCA is a heterogeneous disease and many molecular methods have been used in the search to determine the mechanism of the development of the disease, and to find new diagnostic and prognostic markers (Hughes et al., 2005; Quinn et al., 2005). Our study has demonstrated new genetic networks and biological pathways in both up- and down-regulated gene expression levels. It should be kept in mind that there are certain limits to in 
Table 3. List of the genes in most significantly up-regulated top ten canonical pathways.

\begin{tabular}{|c|c|c|c|}
\hline Pathway & $\begin{array}{c}-\log \\
(P \text {-value })\end{array}$ & Ratio & Molecules \\
\hline Acute phase response signaling & $1,33 \mathrm{E}+01$ & $9,88 \mathrm{E}-02$ & $\begin{array}{l}\text { TTR, ORM2, C1S, VWF, SAA2, SERPINA3, MAPK12, } \\
\text { HRG, ORM1, FOS, RBP7, TF, F8, CFB, IL1B, SAA1, C4B }\end{array}$ \\
\hline $\begin{array}{l}\text { Hepatic fibrosis/hepatic stellate cell } \\
\text { activation }\end{array}$ & $1,26 \mathrm{E}+01$ & $1,15 \mathrm{E}-01$ & $\begin{array}{l}\text { FGF2, MYL5, ACTA2 (includes EG:59), EGF, } \\
\text { MYH11, MYL9, CXCL3, LY96, EDN1, CCL2, IGF1, IL1B, } \\
\text { EDNRA, AGTR1, PDGFRB }\end{array}$ \\
\hline $\begin{array}{l}\text { NRF2-mediated oxidative stress } \\
\text { response }\end{array}$ & $7,54 \mathrm{E}+00$ & $6,63 \mathrm{E}-02$ & $\begin{array}{l}\text { CUL3, FOS, PRKCD, ACTA2 (includes EG:59), DNAJB7, } \\
\text { DNAJC3, DNAJA2, DNAJC10, ACTG2, ACTC1, TXNRD1, BACH1 }\end{array}$ \\
\hline Actin cytoskeleton signaling & $6,80 \mathrm{E}+00$ & $5,06 \mathrm{E}-02$ & $\begin{array}{l}\text { ARHGEF4, FGF2, MYL5, ACTA2 (includes EG:59), EGF, } \\
\text { MYH11, WASF1, MYL9, GPR65, PPP1R12B, ACTG2, ACTC1, } \\
\text { PDGFRB }\end{array}$ \\
\hline Leukocyte extravasation signaling & $5,44 \mathrm{E}+00$ & $5,32 \mathrm{E}-02$ & $\begin{array}{l}\text { CDH5, MMP3, CXCR4, PRKCD, ACTA2 (includes EG:59), } \\
\text { MMP11, ACTG2, MAPK12, MMP23A, ACTC1 }\end{array}$ \\
\hline Axonal guidance signaling & $5,27 \mathrm{E}+00$ & $3,42 \mathrm{E}-02$ & $\begin{array}{l}\text { DPYSL2, CXCR4, MYL5, EGF, FZD1, EIF4E, MYL9, } \\
\text { EPHA8, IGF1, PRKCD, FZD5, GLI1, PPP3CA, PDGFRB }\end{array}$ \\
\hline Calcium signaling & $5,12 \mathrm{E}+00$ & 4,61E-02 & $\begin{array}{l}\text { MYL9, TPM1, TRPC1, ACTA2 (includes EG:59), MYL5, } \\
\text { RCAN2, TPM2, MYH11, ACTC1, PPP3CA }\end{array}$ \\
\hline Xenobiotic metabolism signaling & $5,10 \mathrm{E}+00$ & $4,38 \mathrm{E}-02$ & $\begin{array}{l}\text { CUL3, MAOB, FMO2, CHST7, PPP2R2A, PRKCD, IL1B, } \\
\text { UGT2B17, NRIP1, CES1 (includes EG:1066), MAPK12 }\end{array}$ \\
\hline Coagulation system & $4,96 \mathrm{E}+00$ & 1,43E-01 & F8, F5, F9, WWF, F3 \\
\hline Complement system & $4,96 \mathrm{E}+00$ & $1,35 \mathrm{E}-01$ & C1S, CFB, CFI, C7, C4B \\
\hline
\end{tabular}

silico analysis. Since there are many different genegene interactions resulting from various cellular/experimental conditions, the edges denoted in the network may not represent the actual causal relationship between genes. Moreover, the probe collection on a chip, which necessarily relies on the coverage and the accuracy of both genomic sequences and clone libraries, presents a serious constraint on its detection power (Liu et al., 2007). Furthermore, confounding factors such as lowabundance potential biomarkers could interfere with several groups of high-abundance proteins in human plasma in which a dynamic concentration range of protein component exists (Cho et al., 2005).

Analysis using IPA software revealed 738 upregulated genes in the progression to $P C A$. These were 466 network eligible genes and 423 Functions-Pathways eligible genes. Often individual genes were found in multiple categories of functions related to cancer development including cell-to-cell signaling and interaction, cell signaling, cell death, cellular growth and proliferation, andcellular movement.

One important gene network was identified around the IL-1 $\beta$ gene (Figure 1). This gene has been reported to be a potent modulator of cellular differentiation and a suitable target for anticancer drug design in PCA (Albrecht et al., 2004). A group of chemokines (CCL20, CCL3, CXCL3, CXCL6, CCL14) were up-regulated around IL-1 $\beta$. Chemokines and their ligands are considered to have a significant role in tumor angiogenesis and cancer metastasis. CCL3, CXCL3, and CXCL6 were reported before in PCA (Akashi et al., 2006; Engl et al., 2006). In particular, CXCL3 were found to be highly up-regulated in our study. Other chemokines (MIP-3, MIP-4, MIP-1A, BCA-1, CC-1, MCP-1, TAFA-5, IP-9, CXCR4) were not identified on this network, but they were up- regulated in our study. The CXCR4 gene was reported as up-regulated in leukemia and PCA before (Savli et al., 2002; Engl et al., 2006; Ao et al., 2007). Akashi et al. showed that the expression of androgen receptor (AR) down-regulates the migratory responses of human PCA cells via chemokine and its receptor systems (Akashi et al., 2006). AR is an important molecule in the development of a normal prostate and PCA progress (George, 2003). Amplification of the AR gene has been described in more than $30 \%$ of tumors to prior to therapy (Nelson et al., 1999). Thus, it was reasonable to suppose that chemo- 


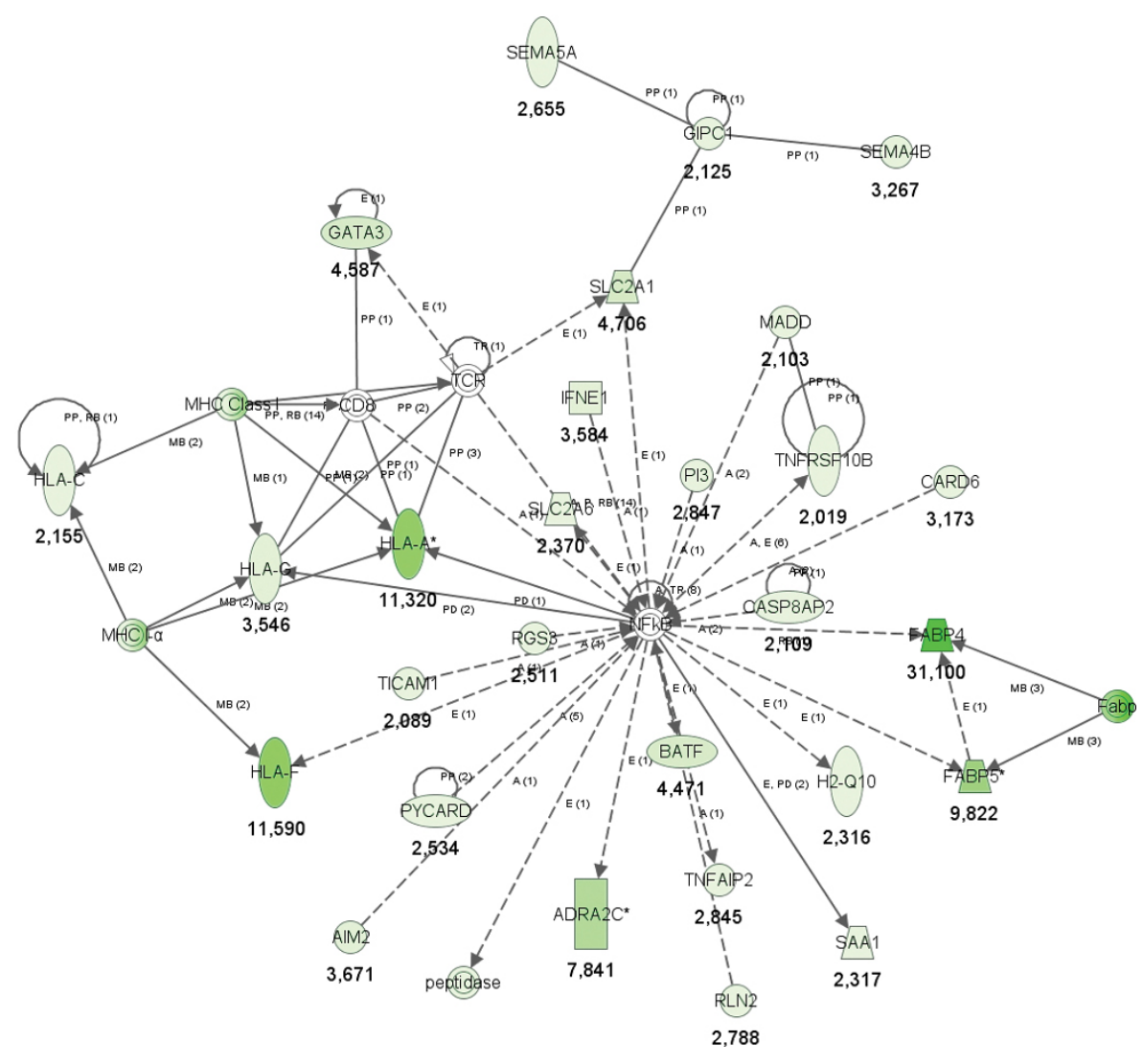

Figure 2. Network contains downregulated genes and identified around NFKB gene. Top functions of the genes were related to cellular assembly and organization, connective tissue development and function, neurological disease. Node (gene) and edge (gene relationship) symbols were described in the bottom part of the figure. The intensity of the node color (green) indicated the degree of downregulation. Genes in uncolored notes were not identified as differentially expressed in our experiment and were integrated into the computationally generated networks on the basis of the evidence stored in the IPA knowledge memory indicating a relevance to this network. The node shapes denote enzymes $(\diamond)$, phosphatases $(\triangle)$, kinases $(\nabla)$, peptidases $(\triangleright)$, G-protein coupled receptor ( $\square$ ), transmembrane receptor ( $(1)$, cytokines $(\square)$, growth factor $(\square)$, ion channel (i), transporter ( translation factor $(\bigcirc)$, nuclear receptor ( $\square$ ), transcription factor $(\checkmark)$ and other (O).

Table 4. List of the genes in most significantly down-regulated top ten canonical pathways.

\begin{tabular}{|c|c|c|c|}
\hline Pathway & -log $(P$-value $)$ & Ratio & Molecules \\
\hline Axonal Guidance Signaling & $1,16 \mathrm{E}+01$ & 4,89E-02 & $\begin{array}{l}\text { PIK3C2B, NGEF, RGS3, SEMA5A, RAC1, KRAS, PLXNA2, GNA14, } \\
\text { ROR1 (includes EG:4919), EPHB6, FGFR3, NFAT5, ARPC2, } \\
\text { ARHGEF6, GNAO1, ABLIM3, ERBB2, SEMA4B, RTN4R, PPP3CA }\end{array}$ \\
\hline Arachidonic Acid Metabolism & $1,00 \mathrm{E}+01$ & $5,69 \mathrm{E}-02$ & $\begin{array}{l}\text { GRN, LTA4H, PTGES2, AKR1C3, CYP19A1, PLA2G10, GPX2, } \\
\text { CYP4Z1, CYP4F3, CYP2J2, ALOX5, CYP2D9 }\end{array}$ \\
\hline $\begin{array}{l}\text { LPS/IL-1 Mediated Inhibition of } \\
\text { RXR Function }\end{array}$ & $9,31 \mathrm{E}+00$ & 6,77E-02 & $\begin{array}{l}\text { GSTP1, MGMT, ALDH1L1, ABCG1, SULT1A2, MAOB, FABP5, } \\
\text { ACSL5, ALAS1, FABP4, HS3ST1, ABCC3, RXRA }\end{array}$ \\
\hline ERK/MAPK Signaling & $7,94 \mathrm{E}+00$ & 5,91E-02 & $\begin{array}{l}\text { PPARG, FGFR3, MYC, PIK3C2B, PPP2CB, ELF3, PLA2G10, } \\
\text { PPP2R2B, RAC1, DUSP4, KRAS, ROR1 (includes EG:4919) }\end{array}$ \\
\hline Xenobiotic Metabolism Signaling & $7,85 \mathrm{E}+00$ & $5,18 \mathrm{E}-02$ & $\begin{array}{l}\text { PIK3C2B, GSTP1, UGT1A6, MGMT, ALDH1L1, KRAS, SULT1A2, } \\
\text { PPP2CB, MAOB, PPP2R2B, HS3ST1, ABCC3, RXRA }\end{array}$ \\
\hline $\begin{array}{l}\text { Metabolism of Xenobiotics by } \\
\text { Cytochrome P450 }\end{array}$ & $7,59 \mathrm{E}+00$ & 4,69E-02 & $\begin{array}{l}\text { GSTP1, AKR1C3, UGT1A6, DHRS2 (includes EG:10202), CYP19A1, } \\
\text { CYP4Z1, ADH1B, ALDH1L1, CYP2J2, CYP2D9 }\end{array}$ \\
\hline Antigen Presentation Pathway & $6,83 E+00$ & 1,54E-01 & HLA-DRB4, HLA-A, HLA-G, HLA-DRB5, HLA-F, HLA-C \\
\hline Eicosanoid Signaling & $6,53 E+00$ & 8,33E-02 & GRN, LTA4H, PTGES2, AKR1C3, PLA2G10, ALOX5, DPEP2 \\
\hline Ephrin Receptor Signaling & $6,13 E+00$ & 4,81E-02 & $\begin{array}{l}\text { EPHB6, FGFR3, NGEF, RGS3, ARPC2, GNAO1, RAC1, KRAS, } \\
\text { GNA14, ROR1 (includes EG:4919) }\end{array}$ \\
\hline Actin Cytoskeleton Signaling & $6,07 \mathrm{E}+00$ & $4,28 \mathrm{E}-02$ & $\begin{array}{l}\text { FGFR3, PIK3C2B, ACTB, ARPC2, FGF9, ARHGEF6, RAC1, KRAS, } \\
\text { ROR1 (includes EG:4919), BDKRB1, TMSB4X }\end{array}$ \\
\hline
\end{tabular}


kines and their ligands were highly important in the progression to PCA. Here we present a group of chemokine up-regulation in the most significant gene work of our study.

The SELE gene was a highly up-regulated member of the network around the IL-1 $\beta$ gene. Bhaskar et al. (2003) found up-regulated SELE levels in another microarray study on PCA. The role of this gene has been described in metastatic prostate tumor cells as well (Dimitroff et al., 2004). Other adhesion molecules (Selectin P, desmolin, Endothelin1, Endothelin RecA, vimentin, PECAM1 , etc.) were not identified on this network, but they were up-regulated in our study as well.

Three serum amyloid protein coding genes (SAA, SAA1, SAA2) were highly up-regulated in the network around the IL-1 $\beta$ gene. Alterations in the expression of serum amyloid proteins have been linked to many tumors such as osteosarcoma (Kovacevic et al., 2008), lung cancer (Dai et al., 2007), renal cell carcinoma (Engwegen et al., 2007), gastric cancer (Chan et al., 2007), and choriocarcinoma (Kovacevic et al., 2007). Serum amyloid protein coding genes are not specific markers for any particular type of tumor. We recommend these genes for monitoring disease activity and response to therapy in patients with PCA.

One network was identified around the insulinlike growth factor 1 (IGF-1) gene (Figure 1). This gene has been linked to PCA before (Abate-Shen and Shen, 2000). Other growth factors (IGFB7, GHBP, URG, and PDF) were not identified on this network, but they were up-regulated in our study.

Another network was identified around the NFKB gene (Figure 1). The angiotensin II receptor type 1 gene was highly up-regulated. This gene could also be a good target for the therapy of prostate cancer (Uemura et al., 2006). Further studies are required to establish the role this gene plays in PCA.

Our study has also demonstrated up-regulated apoptosis related genes (FAS, BIC, PACAP, BFL1) and up-regulated oncogene partners (PET-1, LAF4, HSP2123-like). FAS is the most conspicuous gene among them. Up-regulated FAS levels were reported in PCA previously (lacopino et al., 2006). Well-known oncogenes such as Ras (Konishi, 1992), or apoptosis related genes such as BCL2 (McDonnell, 1992) were found in PCA progress previously, but we did not confirm them in this study.

Canonical pathway analysis revealed that "acute phase response" was the most significant signaling pathway modulated by the up-regulated genes in PCA (See Supplementary Figure 1). Dysregulation of IL-6-type cytokine signaling was reported to contribute to PCA previously (Heinrich et al., 2003). The genes that we found up-regulated were using the IL 1 type cytokine signaling on an extracellular level. Then, interactions were determined among p38 MAPK and c-fos in the nucleus, but it is not easy to determine the pathway that really participated in prostate tumorigenesis since many other pathway members were not detected.

Another significant signaling pathway is hepatic fibrosis/hepatic stellate cell activation (See Supplementary Figure 3). Changes in prostate-specific antigen levels among cirrhotic patients have been reported before (Kubota et al., 1999; Akdogan et al., 2002) but further research is needed to establish whether these genes are new molecular markers or not.

The actin cytoskeleton pathway was highly significant. This pathway has been reported many times in PCA before (Moore et al., 2000; Papakonstanti et al., 2003; Wells et al., 2005; Marelli et al., 2006). Genes belonging to the coagulation pathway were found to be distinctly up-regulated (See Supplementary Figure 2). Patients with PCA may have life-threatening coagulation complications due to their disease. The pathophysiology of disseminated intravascular coagulopathy in patients with prostate cancer is not completely understood. Investigators reported coagulation disorders as early or late signs in PCA (Bern, 2005; Navarro et al., 2006; Duran and Tannock, 2007; Shirai and Chaudhary, 2007). We found highly up-regulated F8, F5, F9, VWF, and F3 gene accumulation around ca-dependent and ca-phospholipid dependent regions of the coagulation pathway. These regions could be the subject of studies to understand the pathophysiology and plan further therapeutic interventions.

Analysis using IPA software revealed that 515 mapped down-regulated genes were detected in the progression to PCA. These were 363 network eligible genes and 342 Functions-Pathways eligible genes. Often individual genes were found in multiple categories of functions related to cell-tocell signaling and interaction, cell signaling, immune response, cancer, cellular growth and proliferation, nucleic acid metabolism, cellular assembly and organization, and connective tissue development and function.

One important down-regulated carcinogenic gene network was identified around the NFKB gene (Figure 2). We observed some down-regulated genes, ADRA2C, FABP4, and FABP5, which were not reported in cancer progress before. Moreover, five genes belonging to $\mathrm{MHC}$ were strictly downregulated in this network (H2-Q10, HLA-A, HLA-C, HLA-F, and HLA-G). Tamura et al. (2007) observed 
down-regulation of HLA-A antigen in microarray analysis of hormone-refractory prostate cancer. We report the down-regulation of four genes (H2-Q10, HLA-C, HLA-F, and HLA-G) here for the first time.

Canonical pathway analysis revealed that "antigen presentation" was an important pathway modulated by the down-regulated genes in PCA. Our findings on MHC genes were related to down-regulation of MHC $\mathrm{I}-\alpha$ and MHC II- $\beta$ class genes (See Supplementary Figure 4).

Axonal guidance signaling was the most significant down-regulated canonical pathway (See Supplementary Figure 5). The FGFR3 gene showed the highest value of under-expression. Fibroblast growth factors (FGFs) and their receptors (FGFRs) have a critical function for the development and homeostasis of the human prostate. Imbalance in expression of these factors is associated with malignancy. We found three members of this family (FGFR3, PIK3C2B, and RAC1) to be downregulated. RAC1 and FGFR3 were evaluated in previous studies (Kwabi-Addo et al., 2001; Gowardhan et al., 2005; Chaffer et al., 2007; Wu et al., 2007), but here we report PIK3C2B gene down-regulation and its relationship to PCA for the first time.Two important gene members of this pathway were down-regulated. K-RAS is not only an oncogene, but also a known target in differentiation therapy of PCA (Benbrahim-Tallaa et al., 2005, 2007). ERBB2 overexpression is important in PCA and our finding is in concordance with previous observations (Liu et al., 2001; Calvo et al., 2003; Ullén et al., 2005). Taken together, two well-known genes, FOS and IL1B, were upregulated as members of the same pathway as well. Axonal guidance signaling in the progress of PCA needs further investigation.

There are different valuable bioinformatic approaches in the literature to analyze prostate cancer progression. Tomlins et al. (2007) profiled prostate cancer progression from benign epithelium to metastatic disease. They identified expression signatures, and analyzed these signatures in the context of a compendium of molecular concepts. Their strategy allowed them to make several insights into disease progression. In the present study we analyzed over one thousand altered genes regarding functions and communications using the IPA tool and detected new relationships.

Our data provide not only new networks between the genes for understanding the biologic properties of PCA but also useful common pathway maps for future understanding of disease and construction of new therapeutic targets. Further combined genomic and proteomic studies are necessary to find out more details of the hierarchy and regulation on DNA-RNA-protein levels.

\section{References}

Abate-Shen C, Shen MM. Molecular genetics of prostate cancer. Genes Dev 2000;14:2410-34

Akashi T, Koizumi K, Nagakawa O, Fuse H, Saiki I. Androgen receptor negatively influences the expression of chemokine receptors (CXCR4, CCR1) and ligand-mediated migration in PCA DU-145. Oncol Rep 2006;16:831-6

Akdogan M, Hassoun BS, Gurakar A, El-Sahwi K, Jazzar A, Wright H, Sebastian A, Nour B. Prostate-specific antigen levels among cirrhotic patients. Int J Biol Markers 2002;17: 161-4

Albrecht M, Doroszewicz J, Gillen S, Gomes I, Wilhelm B, Stief T, Aumüller G. Proliferation of PCA cells and activity of neutral endopeptidase is regulated by bombesin and IL1 beta with IL-1beta acting as a modulator of cellular differentiation. Prostate 2004;58:82-94

Ao M, Franco OE, Park D, Raman D, Williams K, Hayward SW. Cross-talk between paracrine-acting cytokine and chemokine pathways promotes malignancy in benign human prostatic epithelium. Cancer Res 2007;67:4244-53

Benbrahim-Tallaa L, Waterland RA, Styblo M, Achanzar WE, Webber MM, Waalkes MP. Molecular events associated with arsenic-induced malignant transformation of human prostatic epithelial cells: aberrantgenomic DNA methylation and K-ras oncogene activation. Toxicol Appl Pharmacol 2005; 206:288-98

Benbrahim-Tallaa L, Webber MM, Waalkes MP. Mechanisms of acquired androgen independence during arsenicinduced malignant transformation of human prostate epithelial cells. Environ Health Perspect 2007;115:243-7

Bern MM. Coagulopathy, following medical therapy, for carcinoma of the prostate. Hematology 2005;10:65-8

Bhaskar V, Law DA, Ibsen E, Breinberg D, Cass KM, DuBridge RB, Evangelista F. E-selectin up-regulation allows for targeted drug delivery in prostate cancer. Cancer Res 2003;63:6387-94

Calvo BF, Levine AM, Marcos M, Collins QF, lacocca MV, Caskey LS, Gregory CW, Lin Y, Whang YE, Earp HS, Mohler $\mathrm{JL}$. Human epidermal receptor-2 expression in prostate cancer. Clin Cancer Res 2003;9:1087-97

Chaffer CL, Dopheide B, Savagner P, Thompson EW, Williams ED. Aberrant fibroblast growth factor receptor signaling in bladder and other cancers. Differentiation 2007;75:831-42

Chan DC, Chen CJ, Chu HC,Chang WK, Yu JC, Chen YJ, Wen LL, Huang SC, Ku CH, Liu YC, Chen JH. Evaluation of serum amyloid $A$ as a biomarker for gastric cancer. Ann Surg Oncol 2007;14:84-93

Cho SY, Lee EY, Lee JS, Kim HY, Park JM, Kwon MS, Park YK, Lee HJ, Kang MJ, Kim JY, Yoo JS, Park SJ, Cho JW, Kim HS, Paik YK. Efficient prefractionation of low-abundance proteins in human plasma and construction of a two- 
dimensional map. Proteomics 2005;5:3386-96

Dai S, Wang X, Liu L, Liu J, Wu S, Huang L, Xiao X, He D. Discovery and identification of Serum Amyloid A protein elevated in lung cancer serum. Sci China C Life Sci 2007;50:305-11

Dimitroff CJ, Lechpammer M, Long-Woodward D, Kutok JL. Rolling of human bone-metastatic prostate tumor cells on human bone marrow endothelium under shear flow is mediated by E-selectin. Cancer Res 2004;64:5261-9

Duran I, Tannock IF. Disseminated intravascular coagulation as the presenting sign of metastatic prostate cancer. J Gen Intern Med 2007;22:1062

Engl T, Relja B, Blumenberg C, Müller I, Ringel EM, Beecken WD, Jonas D, Blaheta RA. Prostate tumor CXC-chemokine profile correlates with cell adhesion to endothelium and extracellular matrix. Life Sci 2006;78:1784-93

Engwegen JY, Mehra N, Haanen JB, Bonfrer JM, Schellens $\mathrm{JH}$, Voest EE, Beijnen JH. Validation of SELDI-TOF MS serum protein profiles for renal cell carcinoma in new populations. Lab Invest 2007;87:161-72

George NJ. Prostate cancer biology, diagnosis and management. Surg Oncol 2003;12: 211

Gowardhan B, Douglas DA, Mathers ME, McKie AB McCracken SR, Robson CN, Leung HY. Evaluation of the fibroblast growth factor system as a potential target for therapy in human prostate cancer. Br J Cancer 2005;92 320-7

Heinrich PC, Behrmann I, Haan S, Hermanns HM, MüllerNewen G, Schaper F. Principles of interleukin (IL)-6-type cytokine signalling and its regulation. Biochem J 2003 $374: 1-20$

Hughes C, Murphy A, Martin C, Sheils O, O'Leary J. Molecular pathology of PCA. J Clin Path 2005;58:673-84

lacopino F, Angelucci C, Lama G, Zelano G, La Torre G, D'Addessi A, Giovannini C, Bertaccini A, Macaluso MP, Martorana G, Sica G. Apoptosis-related gene expression in benign prostatic hyperplasia and prostate carcinoma Anticancer Res 2006;26:1849-54

Ishigami T, Uzawa K, Higo M, Nomura H, Saito K, Kato Y, Nakashima D, Shiiba M,Bukawa H, Yokoe H, Kawata T, Ito $\mathrm{H}$, Tanzawa H. Genes and molecular pathways related to radioresistance of oral squamous cell carcinoma cells. Int J Cancer 2007;120:2262-70

Konishi N. K-ras activation and ras p21 expression in latent prostatic carcinoma in Japanese men. Cancer 1992;69: 2293-9

Kovacevic A, Hammer A, Sundl M, Pfister B, Hrzenjak A, Ray A, Ray BK, Sattler W, Malle E. Expression of serum amyloid A transcripts in human trophoblast and fetal-derived trophoblast-like choriocarcinoma cells. FEBS Lett 2006;580: 161-7

Kovacevic A, Hammer A, Stadelmeyer E, Windischhofer W, Sundl M, Ray A, Schweighofer N, Friedl G, Windhager R, Sattler W, Malle E. Expression of serum amyloid A transcripts in human bone tissues, differentiated osteoblast-like stem cells and human osteosarcoma cell lines. J Cell Biochem
2008;103:994-1004

Kubota Y, Sasagawa I, Sinzawa H, Kunii T, Itoh K, Miura H, Imai K, Nakada T. Serum levels of free and total prostatespecific antigen in males with liver cirrhosis. Eur Urol 1999;36:409-12

Kwabi-Addo B, Ropiquet F, Giri D, Ittmann M. Alternative splicing of fibroblast growth factor receptors in human prostate cancer. Prostate 2001;46:163-72

Liu F, Jenssen TK, Trimarchi J, Punzo C, Cepko CL, Ohno-Machado L, Hoviq E, Patrick Kuo W. Comparison of hybridization-based and sequencing-based gene expression technologies on biological replicates. BMC Genomics 2007:8:153

Liu HL, Gandour-Edwards R, Lara PN Jr, de Vere White R, LaSalle JM. Detection of low level HER-2/neu gene amplification in prostate cancer by fluorescence in situ hybridization. J Cancer 2001;7:395-403

Maitland NJ, Collins A. A tumour stem cell hypothesis for the origins of PCA. BJU Int 2005;96:1219-23

Marelli MM, Moretti RM, Procacci P, Motta M, Limonta P. Insulin-like growth factor-I promotes migration in human androgen-independent prostate cancer cells via the alphavbeta3 integrin and PI3-K/Akt signaling. Int J Oncol 2006;28:723-30

McDonnell TJ. Expression of the protooncogene bcl-2 in the prostate and its association with emergence of androgenindependent prostate cancer. Cancer Res 1992;52:6940-4

Moore TM, Garg R, Johnson C, Coptcoat MJ, Ridley AJ, Morris JD. PSK, a novel STE20-like kinase derived from prostatic carcinoma that activates the c-Jun $\mathrm{N}$-terminal kinase mitogen-activated protein kinase pathway and regulates actin cytoskeletal organization. J Biol Chem 2000; 275:4311-22

Müller $\mathrm{H}$, Brenner $\mathrm{H}$. Urine markers as possible tools for PCA screening: review of performance characteristics and practicality. Clin Chem 2006;52:562-73

Navarro M, Ruiz I, Martin G, Cruz JJ. Patient with disseminated intravascular coagulation as the first manifestation of adenocarcinoma of the prostate. Risks of prostatic biopsy. Prostate Cancer Prostatic Dis 2006;9:190-1

Nelson MA, Porterfield BW, Jacobs ET, Clark LC. Selenium and prostate cancer prevention. Semin Urol Oncol 1999;17: 91-6

Papakonstanti EA, Kampa M, Castanas E, Stournaras C. A rapid, nongenomic, signaling pathway regulates the actin reorganization induced by activation of membrane testosterone receptors. Mol Endocrinol 2003;17:870-81

Quinn DI, Henshall SM, Sutherland LR. Molecular markers of PCA outcome. Eur J Cancer 2005;41:858-87

Savli H, Aalto Y, Nagy B, Knuutila S, Pakkala S. Gene expression analysis of 1,25(OH)2D3-dependent differentiation of HL-60 cells: a cDNA array study. $\mathrm{Br} \mathrm{J}$ Haematol 2002;118:1065-70

Shirai K, Chaudhary UB. Use of low molecular weight heparin and aminocaproic acid in chronic DIC associated with 
prostate cancer--a case report. Scientific World J 2007; 7:753-5

Tamura K, Furihata M, Tsunoda T, Ashida S, Takata R, Obara W, Yoshioka H, Daigo Y, Nasu Y, Kumon H, Konaka H, Namiki M, Tozawa K, Kohri K, Tanji N, Yokoyama M, Shimazui T, Akaza H, Mizutani Y, Miki T, Fujioka T, Shuin T, Nakamura Y, Nakagawa $\mathrm{H}$. Molecular features of hormone-refractory prostate cancer cells by genome-wide gene expression profiles. Cancer Res 2007;67:5117-25

Tomlins SA, Mehra R, Rhodes DR, Cao X, Wang L, Dhanasekaran SM, Kalyana- Sundaram S, Wei JT, Rubin MA, Pienta KJ, Shah RB, Chiannaiyan AM. Integrative molecular concept modeling of prostate cancer progression. Nat Genet 2007;39:41-51
Uemura $\mathrm{H}$, Ishiguro $\mathrm{H}$, Kubota $\mathrm{Y}$. Angiotensin II receptor blocker: possibility of antitumor agent for prostate cancer. Mini Rev Med Chem 2006;6:835-44

Ullén A, Lennartsson L, Harmenberg $U$, Lennernäs $B$, Majumder K, Holmberg AR, Nilsson S, Elmberger GP. Prostate cancer cell lines lack amplification: overexpression of HER2. Acta Oncol 2005;44:490-5

Wells CM, Ahmed T, Masters JR, Jones GE. Rho family GTPases are activated during HGF-stimulated prostate cancer-cell scattering. Cell Motil Cytoskeleton 2005;62: 180-94

Wu Z, McRoberts KS, Theodorescu D. The role of PTEN in prostate cancer cell tropism to the bone micro-environment. Carcinogenesis 2007;28:1393-400 